\title{
Design of wall materials based on waste glass regeneration
}

\author{
Shao Yang-shi ${ }^{1}$,Fan Ding-qiang ${ }^{2}$, Zhang jing-ming $^{1, \text { a }}$, Ren shi-rui ${ }^{3}$,Wang jin-xin ${ }^{1}$,Luo xu-cong ${ }^{4}$, Peng yun-hui $^{1}$,Hou \\ huan-ran ${ }^{1}$ \\ ${ }^{1}$ School of Materials Science and Engineering, Wuhan University of Technology, Wuhan 430070, China \\ ${ }^{2}$ School of Civil Engineering and Architecture, Wuhan University of Technology, Wuhan 430070,China \\ ${ }^{3}$ School of Navigation, Wuhan University of Technology, Wuhan 430070, China \\ ${ }^{4}$ School of Economics, Wuhan University of Technology, Wuhan 430070, China
}

\begin{abstract}
With urban high buildings increasing in China, the demand for efficiency of wall insulation is getting more and more serious, especially in northeast and northwest China. However, thermal insulation wall in domestic is quite easy to produce cracks under external conditions, which greatly reduces life time. In this paper, we expand the discarded glass and mix aggregate and polypropylene fiber to improve the compressive strength of concrete to achieve green multifunctional concrete. Through the performance test of the expansive glass, we conclude that performances of expansive glass become best at the sinter point of $660^{\circ}$; Moreover, $\mathrm{TiO}_{2}$ added to the exterior wall coating can catalyze the degradation of nitrogen oxides and formaldehyde to purify the air. Non-toxic and harmless, the wall, with strong thermal insulation efficiency, is expected to replace the current building materials in order to produce and utilize massively.
\end{abstract}

\section{Introduction}

Due to the cold winter in northeastern and northwestern China, residential houses mostly achieve the better thermal insulation efficiency through increasing the thickness of wall. Relevant areas keep warm by using thermal power generation and coal-fired boilers, which, which, however enhance the burden to supply heating because of the poor insulation of houses. At present, major measures taken to solve the wall heat preservation problem in domestic is to design triple wall structures, which is is vulnerable to external conditions as heat, coldness and frost, resulting in getting walls mildewed and cracked. In addition, it makes the wall thick up to $400 \mathrm{~mm}$ which has a negative impact on the environment, for a lot of cement is consumed during the whole construction process because of the high energy consumption and pollution from cement.

As for the insulation wall, scholars at home and abroad have also carried out related research. Wu zhimin etc. [1] analyzed the technical characteristics of the self-insulation wall and listed six different application conditions of self-insulation wall technology in different fields.; Zhu yan etc. [2] used the building energy simulation software to compare the insulation structure of the internal and external walls and concluded that the inner wall insulation was more environmental protection and energy saving.;Wang, etc. ${ }^{[3]}$ simulated the heat transfer of self-insulating foam concrete in the study on heat transfer performance of foam concrete self-insulation wall and concluded that the insulation of external thermal insulation is greater than that of internal insulation because foam concrete has the best indoor thermal environment..Huang $\mathrm{Pei}^{[4]}$ analyzed the advantages of precast concrete sandwich insulation wall. At present, there are many researches on the insulation wall at home and abroad, but the application of abandoned glass in the insulation wall is still in its initial stage. This article studies a kind of multifunctional green building materials based on waste glass's regeneration. The glass is expanded by a set of processes, and then the expansive waste glass is replaced with the aggregate stone in the concrete. Then we add polypropylene fiber in concrete to improve its compressive strength and obtain green multifunctional concrete. At the same time, a coating of $\mathrm{TiO}_{2}$ is applied to outside wall, which can catalyze the decomposition of harmful gases such as nitrogen oxides and formaldehyde to purify the air. The material has good heat preservation efficiency, increases the energy utilization ratio effectively and reduces the environmental pollution caused by wasted glass, which is expected to replace the current building materials in order to produce and utilize massively.

\section{Preparation of wall materials}

\subsection{Preparation of expansive glass}

Expansive glass recycled in the urban cities is cleaned and the steel pestle in the mortar is crushed after being sifted to obtain the glass particles between 76 and 150

* Corresponding author: a 510649035@qq.com 
$\mu \mathrm{m} .6 \mathrm{wt} \%$ of carboxymethyl cellulose (CMC, USP grade, Aladdin chemical reagent company) and a certain content of starch (pharmaceutical grade, Aladdin chemical reagent company) are added to glass particles, with the CMC as adhesive while starch as pore-forming agent of porous glass. The mixed powder is mixed with $20 \mathrm{wt} \%$ of deionized water and stirred evenly. The blank is molded into a rod and a circle with a diameter of 20 $\mathrm{mm}$ under the compressive stress of $32 \mathrm{MPa}$. Compact is dried 24 hours under the temperature of $105{ }^{\circ} \mathrm{C}$ and sintered in the muffle furnace at the rate of $10{ }^{\circ} \mathrm{C} / \mathrm{min}$. Samples need to be insulated $60 \mathrm{~min}$ when up to $550{ }^{\circ} \mathrm{C}$ to ensure that the $\mathrm{CMC}$ and starch are completely decomposed. The flowchart of expansive discarded glass is shown as Fig 1.

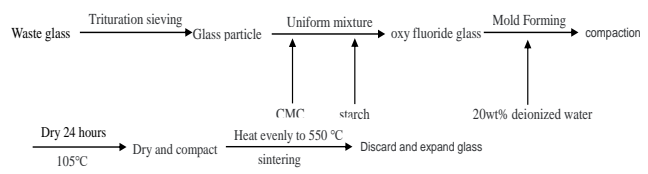

Fig. 1 the flowchart of the abandoned glass expansion process.

\subsection{Preparation of modified latex paint}

Nano $\mathrm{TiO}_{2}$ band-gap is $3.0 \sim 3.2 \mathrm{eV}$, corresponding to a wavelength of $387.5 \mathrm{~nm}$ light energy. In the air with a small amount of water vapor, electrons in the valence band will be inspired to guide when the photon with more energy than the forbidden band width radiation $\mathrm{TiO}_{2}$ surface, which produces highly active free mobile light electrons e-and $\mathrm{h}+$ holes in the valence band and the guide respectively. The electrons and holes generated by the light excitation can be transferred from the body to the surface quickly. The holes is a strong oxidizer, which can oxidize the hydroxyl and $\mathrm{H}_{2} \mathrm{O}$ on the surface of $\mathrm{TiO}_{2}$ as $\cdot \mathrm{OH}$, while the conduction band $\mathrm{e}$ - is a strong reducing agent adsorbed on the surface of $\mathrm{TiO}_{2}$ to form superoxide anion $\mathrm{O}_{2-}$. A part of $\mathrm{O}_{2}$ - will continue to be generated by chain reaction to turn to $\cdot \mathrm{OH}$ with a strong oxidizing ability, which can attack the $\mathrm{C}-\mathrm{H}$ bond of formaldehyde, produce new free radicals with reactive $\mathrm{H}$ atoms and stimulate the chain reaction to decompose formaldehyde into water and $\mathrm{CO}_{2}$. Under the photo catalysis of nano $\mathrm{TiO}_{2}$, organic pollutants can be degraded and even reduced to $\mathrm{CO}_{2}, \mathrm{H}_{2} \mathrm{O}$ and corresponding ions. The basic principle of $\mathrm{TiO}_{2}$ photo catalysis reaction is shown in Fig. 2.

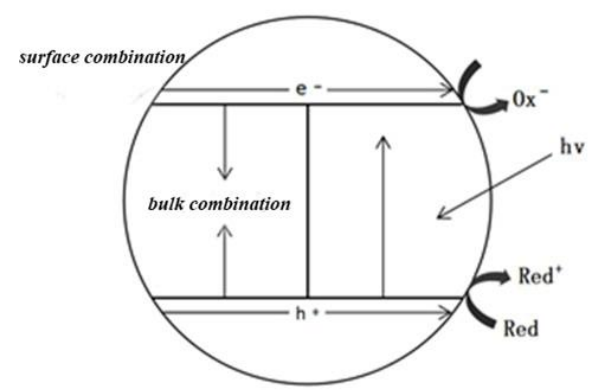

Fig. 2 Schematic diagram of the basic principle of $\mathrm{TiO} 2$ photocatalytic reaction.

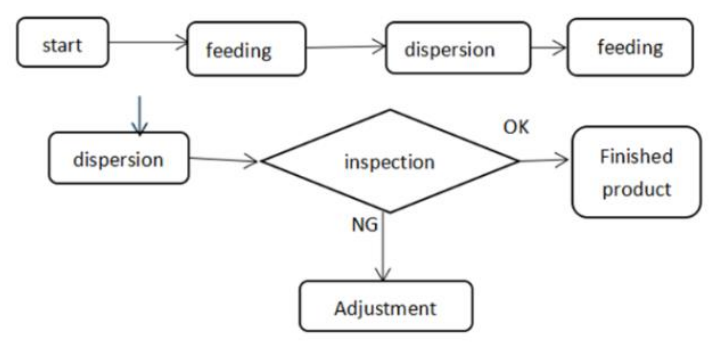

Fig 3 main process flow chart of coating production.

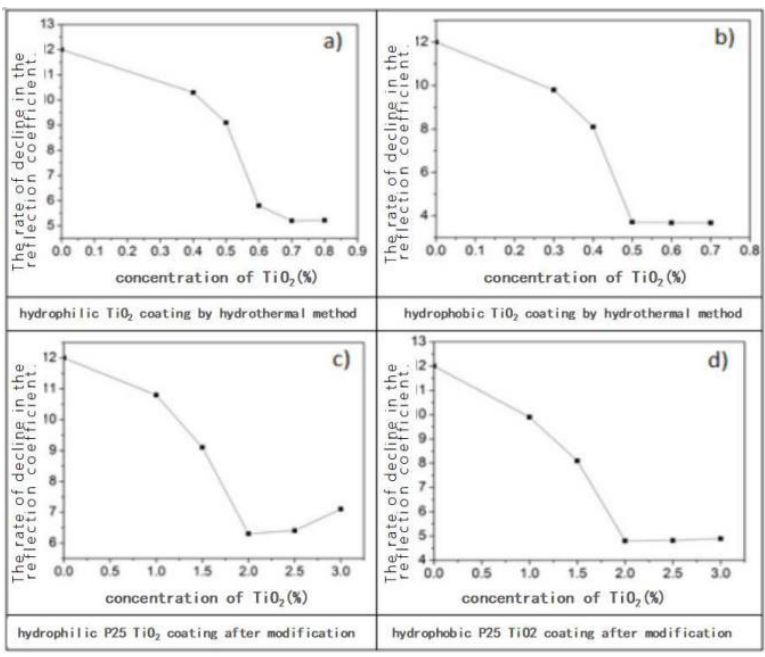

Fig. 4 Influence of $\mathrm{TiO} 2$ concentration on coating resistance.

During the process of preparing coatings with catalytic properties, we adopt two kinds of schemes: One method is to fill the wall coating with nanometer titanium dioxide powder into different mass fraction and test its thermal insulation performance to determine the optimum ratio. Another method is to add nanometer $\mathrm{TiO}_{2}$ powder into the prepared coating, and choose the optimum adding proportion through experiment, which, in other words, adjust coating ratio by the method of using paint coating aging resistance test (select smooth level concrete slab as test plate and put it in different intensity of light, temperature and humidity to evaluate the aging resistance of the coating in order to gain proper coating formula). The optimal choice was obtained by combining the results of the two schemes and the exterior 
wall coating with catalytic performance can be prepared. The optimal concentration of hydrophilic and hydrophobic nano-tio2 slurry are $0.7 \%$ and $0.5 \%$ respectively[5]. The catalytic effect of hydrophobic $\mathrm{TiO}_{2}$ wall is shown in Fig.5.

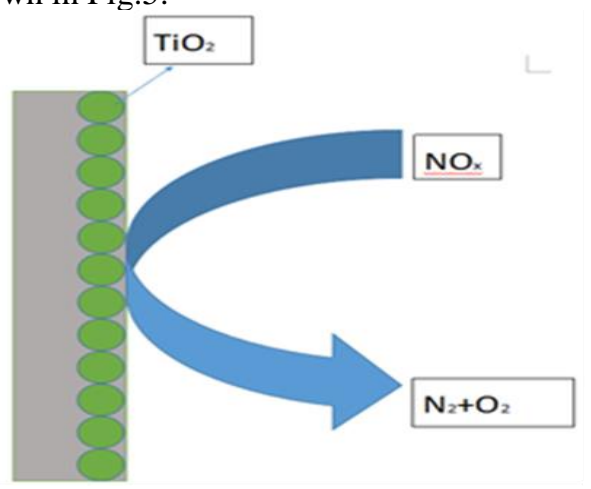

Fig.5 The wall catalytic effect diagram

\subsection{The preparation of insulation super-light fiber concrete}

The cement and the prepared dilatation glass (replace stones as lightweight aggregate concrete) are mixed into the blender in a dry state, added $75 \%$ water, and mixed with super plasticizer and the remaining $25 \%$ water and then mixed with polypropylene fiber gradually till the end. During the whole mixing process, it is necessary to stir to the fullest and shake continuously in order to mix all the raw materials uniformly. The anticipated dry density of super light fiber reinforced concrete is 750 $\mathrm{kg} / \mathrm{m}^{3}$. In this article, two kinds of reinforcing fibers are proposed and the total amount of fiber is adjusted to determine the optimal adding quantity to ensure the optimal concrete mix ratio so as to design the best mechanical property product. Compared with other lightweight concrete of the same density, insulation super light fiber reinforced concrete has better mechanical properties and lower thermal conductivity, which can be used for expansive structures, composition of insulation material and even the application of compressive material production, as the expansive discarded glass is adopted.

\section{Reinforced concrete model of thermal insulation and light fiber}

The expansive discarded glass adopted in this article uses aggregate stones with porous property, low thermal conductivity, low density and other outstanding performance to improve the heat preservation of normal concrete and reduce its density, which can produce thermal insulation. During the design of insulating concrete, we add polypropylene fiber to improve its compressive strength. The optimum parameters of

$$
P(\mathrm{D})=\frac{D^{q}-D_{\min }^{q}}{D_{\max }^{q}-D_{\min }^{q}}
$$

polypropylene fiber are determined by using the modified Andreasen \& Andersen formula model, so as to design the insulation light fiber concrete with the best strength and best performance as the wall material.

In the process of actual production, we reduce the difference between the actual and theoretical dosage according to the variance formula in order to ensure that some errors in the actual operation are minimized. The variance formula is shown in the following (2) and (3)

$$
\begin{aligned}
& R S S=\frac{\sum_{i=1}^{n}\left(\mathrm{P}_{m i x}\left(\mathrm{D}_{i}^{i+1}\right)-\mathrm{P}_{t a r}\left(\mathrm{D}_{i}^{i+1}\right)\right)^{2}}{n} \\
& R^{2}=1-\frac{\sum_{i=1}^{n}\left(\mathrm{P}_{m i x}\left(\mathrm{D}_{i}^{i+1}\right)-\mathrm{P}_{t a r}\left(\mathrm{D}_{i}^{i+1}\right)\right)^{2}}{\sum_{i=1}^{n}\left(\mathrm{P}_{m i x}\left(\mathrm{D}_{i}^{i+1}\right)-\bar{P}_{\text {mix }}\right)^{2}}
\end{aligned}
$$

The expansive discarded glass as light aggregate is recycled and added to the concrete in order to produce extremely light fiber reinforced concrete with high strength, low density and low thermal conductivity, which turns into insulated wall concrete molding material; At the same time, this paper will have the catalytic performance of titanium dioxide powder into the external wall emulsion paint to make the emulsion painting with catalytic performance to paint the surface of wall material.

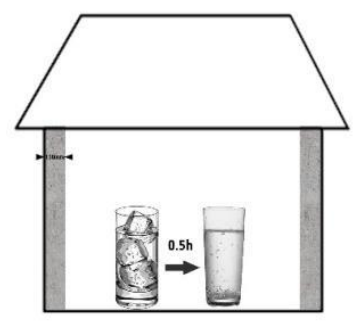

Fig. 6 Common wall

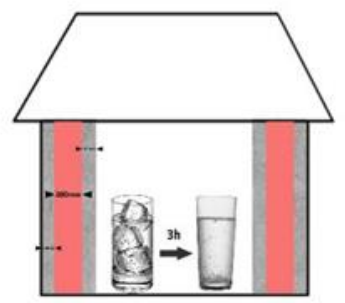

Fig. 7 Ordinary three-layer thickened wall. 


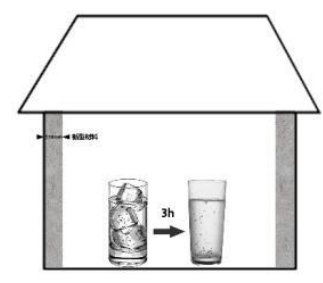

Fig.8 Green multi-function wall

Compared Fig.6 with Fig.8, the melting time of ice in green building materials is six times than that in ordinary wall under the same thickness $(150 \mathrm{~mm})$. Compared Fig.7 with Fig.8. Thickness of the normal thickened wall (triple structures) is $400 \mathrm{~mm}$, which is much thicker than the green multi-function wall under the same thermal insulation effect.

\section{Performance test of expansive glass}

The chemical composition of glass is measured by X-ray fluorescence spectrometer while the particle size distribution is measured by laser particle size instrument. Glass powder of $6 \mathrm{mg}$ was heated to $800^{\circ} \mathrm{C}$ at the speed of $10{ }^{\circ} \mathrm{C} / \mathrm{min}$ to determine the glass transition temperature $(\mathrm{Tg})$ by using differential thermal analyzer. The porosity of glass is determined by Archimedes method while the pore diameter distribution is obtained from the pore diameter distribution analyzer. The bar specimen is polished to the size of $40 \mathrm{~mm} \times 4 \mathrm{~mm} \times 4$ $\mathrm{mm}$. The three-point-bend strength is measured on the universal test machine, the span is set at $32 \mathrm{~mm}$ and the pressure head is reduced by $0.5 \mathrm{~mm} / \mathrm{min}$. Nitrogen and water flow is measured by a homemade flux device. The microscopic appearance of porous glass is observed by scanning electron microscope.

\subsection{Sintering temperature}

The pore distribution of expansive glass is obtained by controlling the sintering temperature so aas to gain the optimum temperature.Through researching for relevant data, the team gains experimental temperatures by grouping experiment as $640{ }^{\circ} \mathrm{C}, 650{ }^{\circ} \mathrm{C}, 660{ }^{\circ} \mathrm{C}$ and $670{ }^{\circ} \mathrm{C}$. The distribution of pore distribution is obtained as follows.

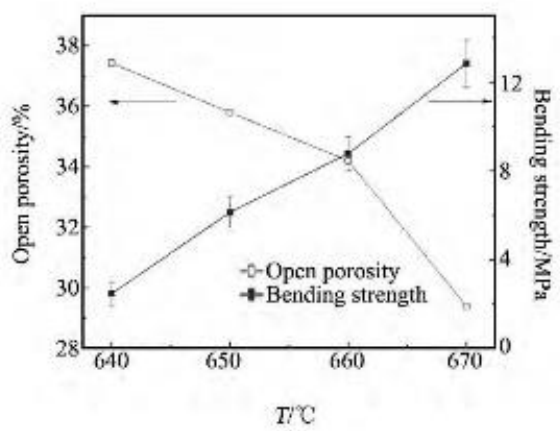

Fig. 9 Influence of different sintering temperature on porosity and bending strength of porous glass.

\subsection{The addition of pore-forming agent}

The mechanical properties of expansive glass are mainly determined by its porosity, so the addition of the pore-making agent is the key to the preparation of expansive glass. In order to study appropriate amount of pore-forming agent in the expansive glass, we intend to choose different starch content of compact ( $0 \%$ to $16 \%$ ) to sinter under $660{ }^{\circ} \mathrm{C}$ for 30 minutes to study pore-forming agent content on the porosity and compressive strength of porous glass, so as to get the results. When the starch content increases from 0 to $12 \%$, the compressive strength of the sample declines from 9.86 $\mathrm{MPa}$ to $8.40 \mathrm{MPa}$ as well as the percent opening rate changes at the same time. Considering most starches were piled into the glass gap among particles because of the deformation after dissolution, the pore-forming agent content has little effect on the performance of the samples. It is observed that when the starch content increases to $16 \%$, the excess starch could reach the effect of opening the pores. By observing the experiment diagram, the appropriate amount of starch is obtained, which achieves optimum mechanical performance.

\subsection{Nitrogen flux and water flux}

In this article, the control variable method is proposed to change the nitrogen flux and water flux of glass by changing the sintering temperature and pressure respectively,which as a result, the corresponding distribution diagram is obtained.The optimum nitrogen flux and water flux is gained by comparative analysis.As figure 7 and figure 8 show, when the temperature achieved $640{ }^{\circ} \mathrm{C}$ to $650{ }^{\circ} \mathrm{C}$, the porosity decreases and gas flux declines as well; When the temperature is up to $660{ }^{\circ} \mathrm{C}$, the porosity is reduced, while gas flux increased slightly because the average pore diameter increases considerably; When the temperature is up to $670{ }^{\circ} \mathrm{C}$, the gas flux reduces as the porosity and average pore diameter decrease. 


\section{Acknowledgment}

The authors were supported financially by students innovation and entrepreneurship training progra (20171049706017)

\section{Reference}

1. Wu Zhimin, Xu Jinfeng, Zhang Yuan, et al. Application of self insulation wall in hot summer and cold winter zone $[\mathrm{J}]$. building energy efficiency, 2009, 37 (5): 8-12.

2. Zhu Yanyan. Numerical simulation and experimental verification of wall insulation in hot summer and cold winter zone [D]. Qingdao University of Science \& Technology, 2017.

3. Wang Haijun, Yao Yong, Chen Dai Guo, et al. Experimental research on heat transfer performance of foam concrete self insulation wall. [J]. construction technology, 2015 (4): 111-115.

4. Huang Pei Yi. Precast concrete sandwich wall insulation characteristics analysis and design of [J]. foreign construction, 2017 (7): 261-263.

5. section East. Preparation of nano $\mathrm{TiO}_{2}$ and surface modification of exterior wall coatings [D]. Chongqing University, 2013.

FIG. 10 (a) nitrogen flux and (b) water flux at different

\section{Conclusion}

Through the above research, this article designs the wall material with the function of thermal insulation and catalytic. On the one hand, this kind of wall material recycles discarded glass which is unable to be degraded, which greatly reduces soil pollution caused by the garbage's landfill and saves land resources which make the recycling rate of discarded glass over $60 \%$. On the other hand, as the thickness of the wall material is $150 \mathrm{~mm}$, while the thickness of the traditional wall material is $400 \mathrm{~mm}$ under the premise of the same thermal insulation effect, the amount of cement can be reduced to a certain extent, which can reduce energy consumption and save energy. As the cement content of the wall material is reduced, the durability of the concrete will be improved and the life time of building will be longer. Thus, the production cost of construction industry will be reduced while the economic benefits will be significant. Through the performance test of expansive glass, the porosity and bending strength are the best when the sintering temperature is around $660^{\circ} \mathrm{C}$. At the same time, the coating with the function of catalytic designed in this project can decomposes harmful gases in the air, purifies the air and reduces air pollutants, which is in good harmony with environment. It can make human living environment more comfortable and healthy, which is in accordance with sustainable development.
6. Wu Haijun, Zhang Xuebin, Liu Jia, et al. Preparation of porous glass [J]. silicate bulletin from waste glass sintering, bulletin 2015, 34 (6): 1725-1729. 